\title{
CORRUPÇÃO PRIVADA E TRATAMENTO INTERNACIONAL
}

\author{
Isabela Andreazza dos Anjos* \\ Fábio André Guaragni*
}

\section{RESUMO}

O presente trabalho tem por objetivo averiguar qual é o tratamento conferido pelos instrumentos internacionais e pela legislação estrangeira à corrupção e, mais especificamente, à corrupção privada. Para tanto, realizando uma pesquisa explanatória e utilizado como procedimento de pesquisa o bibliográfico e o documental, busca-se compreender como a doutrina vem interpretando o tema e avaliar se existe uma orientação quanto à criminalização da corrupção privada no âmbito internacional e consenso quanto aos modelos de tipificação. Ao final, foi observada grande heterogeneidade no que diz respeito aos modelos de tipificação.

PALAVRAS-CHAVES: corrupção; corrupção privada; criminalização; legislações estrangeiras; instrumentos internacionais.

\section{PRIVATE CORRUPTION AND INTERNATIONAL TREATMENT}

\begin{abstract}
The present work aims to find out what is the treatment given by international instruments and foreign legislation to corruption and, more specifically, to private corruption. Therefore, by carrying out an explanatory research and using the bibliographic and documentary research procedure, we seek to understand how the doctrine has been interpreting the theme and assess whether there is an orientation regarding the criminalization of private corruption at the international level and consensus on the models of criminalization. In the end, great heterogeneity was observed with regard to the criminalization models.
\end{abstract}

KEYWORDS: corruption; private corruption; criminalization; foreign laws; international instruments.

\section{INTRODUÇÃO}

Ainda soa estranho para muitos juristas, especialmente latino-americanos, falar em corrupção privada, quando se encontram tão acostumados ao modelo tradicional de corrupção, isto é, aquele que envolve a presença de um funcionário público em um dos polos da conduta criminosa (FOFFANI, 2009).

\footnotetext{
* Mestranda em Direito Empresarial e Cidadania pelo Unicuritiba. Contato: andreazza.anjos@hotmail.com.

* Doutor em Direito das Relações Sociais (UFPR), com estudo Pós-doutoral na Università degli Studi di Milano. Professor de Direito Penal do Mestrado do Unicuritiba e FEMPAR. Contato: guaragni@mppr.mp.br.
} 
Essa postura, contudo, não leva em conta que a temática já é objeto de várias iniciativas supranacionais, que nos últimos anos, na esteira da luta internacional contra a corrupção, buscaram orientar e estimular os Estados a criminalizarem a corrupção privada em âmbito interno.

Para além disso, Aragandoña (2003) observa que não há motivos para crer que a corrupção entre particulares seja menos danosa e menos frequente que a corrupção em seu modelo tradicional. É por essa razão, também, que nas últimas décadas vários organismos internacionais tomaram iniciativas para prevenir a corrupção privada.

Nesse contexto, o presente artigo tem como objetivo analisar o tratamento conferido à corrupção privada pelos diversos países e instrumentos internacionais, avaliando se existe uma orientação quanto à criminalização dessa prática e consenso sobre o modelo de tipificação.

Para tanto, será feita uma pesquisa explanatória (GIL, 2008), utilizado como procedimento de pesquisa o bibliográfico e o documental. A pesquisa bibliográfica envolverá análise da literatura já produzida sobre o tema, publicada em livros e artigos científicos, e revela-se importante por permitir uma maior abrangência de conteúdo. Para a pesquisa documental serão analisados os tratados internacionais que versem sobre o fenômeno da corrupção.

Inicia-se o presente trabalho com uma análise sobre a luta contra a corrupção em âmbito global, uma tendência internacional para frear a ineficiência econômica e garantir livre concorrência e que vem sendo desenvolvida há algumas décadas através de diversos instrumentos internacionais.

Na sequência passa-se a analisar mais especificamente o fenômeno da corrupção privada, buscando-se averiguar como alguns tratados internacionais abordam a temática, além de analisar como a doutrina vem interpretando esses diferentes instrumentos.

Por fim, de forma breve, é feita uma revisão bibliográfica sobre como a doutrina especializada avalia os modelos de tipificação dessa modalidade de corrupção, especialmente no que diz respeito à legislação de países europeus e avaliando a necessidade de intervenção do Direito Penal na coibição da prática corruptiva entre particulares.

Nas considerações finais são tecidos breves apontamentos sobre as informações obtidas, buscando traçar um panorama geral quanto ao tratamento conferido à corrupção privada em âmbito global. 


\section{A CORRUPÇÃO E SEU TRATAMENTO INTERNACIONAL}

Historicamente, a corrupção era concebida como um problema envolvendo funcionários público e políticos "ímprobos", ao mesmo tempo em que se acreditava que os particulares, vítimas do sistema, não tinha opção outra que não se render ao pagamento de propinas e subornos, adequando-se a realidade do país (MARTÍN, 2013).

Essa maneira de conceber a corrupção foi, contudo, nas palavras de Martín (2013, p.191), "enormemente prejudicial e conduz a uma multiplicação exponencial da corrupção" . Até o final da década de 1970 houve tentativas de legitimar a prática, argumentou-se que ela era necessária para tornar o mercado mais funcional e menos burocrático. Em alguns países, inclusive, havia previsão para retorno fiscal do dinheiro despendido com suborno pelos particulares.

Nesse mesmo sentido, Costa (2012) aponta que até a década de 1980, a corrupção era vista por muitos como uma forma de contornar ineficiência econômica gerada em Estados excessivamente burocráticos, além de se mostrar necessária para facilitar a criação de infraestrutura nos países subdesenvolvidos. Acreditava-se que a corrupção seria um mecanismo transitório e que se dissiparia com a democratização. Essa concepção e a ideia de a corrupção era um mal limitado aos países subdesenvolvidos se tornaram ultrapassada por volta da década de 1980.

Com o passar dos anos, os Estados perceberam que as práticas de corrupção não afetavam apenas a Administração Pública, mas também os investidores e a livre concorrência, além de gerarem grande ineficiência econômica, mormente quando constatado que o pagamento de suborno era mais vantajoso do que o investimento em tecnologia. Foi nesse período que a estratégia de combate a corrupção começou a mudar (MARTíN, 2013).

A nova política anticorrupção, então, originou-se nos Estados Unidos em 1977, com o Foreign Corrupt Practices Act (FCPA), embrião da política criminal moderna contra práticas corruptivas, que passou a exigir do setor privado envolvimento e responsabilização na luta contra a corrupção (MARTÍN, 2013).

O FCPA foi aprovado no período que seguiu aos escândalos de corrupção Watergate e quando o Governo estadunidense descobriu que centenas de empresas estadunidenses 
haviam pago grandes somas em suborno para funcionários de governos de outros países, a fim de assegurar os negócios no exterior (USA, 2020).

Na posse dessas informações, o Congresso americano compreendeu que a prática de corrupção impunha grandes custos às empresas, levando a uma ineficiência de mercado, instabilidade, produtos de menor qualidade e "um injusto campo de jogo para negócios honestos" (USA, 2020).

O objetivo do FCPA era coibir e penalizar atos de corrupção de empresas estadunidenses em casos em que a transação envolvia funcionários públicos de outros países. Nesse cenário e diante da nova legislação, as empresas norte-americanas entraram em desvantagem concorrencial no mercado internacional, já que companhias sediadas em outros países não contavam com as mesmas obrigações. Por conta disso, os Estados Unidos começaram a pressionar para que fossem criados instrumentos internacionais a fim de coibir práticas de corrupção ao redor do globo, ao estilo do FCPA (GONTIJO, 2014).

A preocupação com a corrupção deixou de se restringir ao âmbito interno de cada país, na medida em que, com a globalização, os nefastos efeitos econômicos das práticas de corrupção tornam-se transnacionais, conforme esclarece De Brito:

\begin{abstract}
Em um mundo globalizado, não há mais como limitar o tratamento da corrupção a uma lesão exclusiva do bom andamento da Administração Pública estatal e limitada ao território nacional, como costumeiramente se faz nos tradicionais códigos penais do século XIX e XX. As condutas que hoje podem ser incluídas como corrupção afetam relações econômicas de natureza transnacional, e por isso o interesse na comunidade internacional na coalizão e cooperação dos Estados para um efetivo plano de prevenção e repressão. (DE BRITO, 2019, p. 29).
\end{abstract}

A expansão da corrupção e a constatação de sua transnacionalidade, aliada à verificação dos negativos efeitos econômicos trazidos pela prática, fomentaram a preocupação dos Estados na coibição de condutas corruptas (CARNEVALI; ARTAZA, 2017).

Nos anos que se seguiram à edição do FCPA, muitas organizações internacionais aderiram aos esforços de contenção da corrupção e criaram documentos visando ao alinhamento das legislações nacionais sobre o tema, inclusive no que se refere às práticas cometidas no âmbito estritamente privado (GONTIJO, 2014). 
Dentre os referidos instrumentos convém destacar a Convenção das Nações Unidas Contra a Corrupção, a Convenção sobre o Combate à Corrupção de Funcionários Públicos Estrangeiros em Transações Comerciais Internacionais, a Convenção Interamericana Contra a Corrupção, a Convenção Penal Contra a Corrupção do Conselho da Europa, a Ação Comum 98/742/JAI, a Decisão Quadro 2003/568/JAI do Conselho da Europa, sobre as quais serão tecidas breves considerações.

A fim de combater a corrupção em âmbito global e em todas as suas formas a Organização das Nações Unidas promoveu em 2003 a Convenção das Nações Unidas contra a Corrupção, também conhecida como Convenção de Mérida, ratificada pelo Brasil no mesmo ano e promulgada por meio do Decreto no 5.687, de 2006. Em seu preâmbulo, prevê expressamente que: "a corrupção deixou de ser um problema local para converter-se em um fenômeno transnacional que afeta todas as sociedades e economias".

No que se refere à criminalização da corrupção privada, objeto deste estudo, a Convenção apenas recomenda que os Estados signatários consideram a possibilidade de adotar medidas legislativas, e de outras índoles, sobre a temática, conforme artigo 21 da Convenção, nesses termos:

Cada Estado Parte considerará a possibilidade de adotar medidas legislativas e de outras índoles que sejam necessárias para qualificar como delito, quando cometido intencionalmente no curso de atividades econômicas, financeiras ou comerciais:

a) A promessa, o oferecimento ou a concessão, de forma direta ou indireta, a uma pessoa que dirija uma entidade do setor privado ou cumpra qualquer função nela, de um benefício indevido que redunde em seu próprio proveito ou no de outra pessoa, com o fim de que, faltando ao dever inerente às suas funções, atue ou se abstenha de atuar;

b) A solicitação ou aceitação, de forma direta ou indireta, por uma pessoa que dirija uma entidade do setor privado ou cumpra qualquer função nela, de um benefício indevido que redunde em seu próprio proveito ou no de outra pessoa, com o fim de que, faltando ao dever inerente às suas funções, atue ou se abstenha de atuar (ONU, 2003).

Interpretando referida Convenção das Nações Unidas, Sanseverino (2017) defende se tratar do instrumento internacional mais completo com relação à temática da corrupção. Pontua, contudo, no tocante à corrupção privada, que embora o documento exija dos países a criminalização da corrupção praticada na esfera pública, ele apenas incentiva a criminalização da corrupção entre privados. Nesse contexto, cita o entendimento de Ignacio Gómez de la 
Torre e Giorgio Cerina para os quais bastaria que os países promovessem internamente um debate acerca do tema, ainda que optando por não tipificar a prática, a fim de cumprir a Convenção (SANSEVERINO, 2017).

Cabe observar aqui que o Brasil ratificou a referida Convenção, indicando ter assumido compromisso com a reflexão sobre eventual tipificação da corrupção privada no país. Ainda assim, David (2019) alerta que a mera indicação internacional,desacompanhada de maiores reflexões sobre o tema em âmbito interno, não pode ser suficiente para levar à tipificação da conduta, pois é necessário garantir qualidade dogmática à tipificação.

Sob outro aspecto, Sanseverindo (2017) aponta que relevantes debates envolvendo a corrupção privada antecederam a redação da Convenção das Nações Unidas Contra a Corrupção. Previamente à definição da redação final, países puderam submeter a um Comitê ad hoc sugestões de texto para o dispositivo.

Segundo o autor, apesar dos debates prévios e da possibilidade de votação para a escolha do modelo a ser adotado, ainda houve resistência quanto à previsão de obrigatoriedade de criminalizar a conduta, diante do receio do impacto econômico que a norma penal poderia gerar em âmbito interno (SANSEVERINO, 2017).

Para Gontijo (2014), e diferentemente de outros textos internacionais, a Convenção de Mérida não prevê a proteção da concorrência ao fomentar a criminalização da conduta de corrupção privada, mas sim visa o "aprimoramento" da integridade e honestidade nas relações privadas.

A Convenção da OCDE sobre o Combate à Corrupção de Funcionários Públicos Estrangeiros em Transações Comerciais Internacionais foi editada após forte pressão dos Estados Unidos, que buscavam incentivar o restante do mundo a adotar medidas de combate à corrupção semelhantes ao já citado FCPA. A despeito de sua importância, o documento não faz previsões expressas acerca da criminalização da corrupção entre particulares, justamente porque seu principal enfoque foi a punição daqueles que subornassem funcionários públicos estrangeiros (OCDE, 1997).

No âmbito interamericano, a Convenção Interamericana Contra a Corrupção, adotada em Caracas em 1996, reconheceu em seu preâmbulo os efeitos nocivos da corrupção, alertando para o risco que o fenômeno gera para as instituições democráticas e para a economia e identificando seu caráter muitas vezes transnacional, defendendo que, como tal, deve ser combatida, a partir de uma ação coordenada dos Estados (OEA, 1996). 
Não há, contudo, disposições envolvendo a corrupção privada, não se preocupando a Convenção com as práticas corruptas que acontecem exclusivamente entre particulares, conforme alertam Carnevali e Artaza (2017).

No âmbito da União Europeia, a Convenção Penal Sobre a Corrupção, celebrada em Estrasburgo em 1999, determina em seus artigos $7^{\circ}$ e $8^{\circ}$ que os estados signatários adotem medidas legislativas a fim de classificar como infração penal a corrupção privada, consistente no ato cometido intencionalmente, no âmbito de uma atividade comercial, de prometer oferecer ou entregar ou, no modelo passivo, pedir ou receber, direta ou indiretamente, qualquer vantagem indevida a qualquer pessoa que seja dirigente ou que trabalhe para entidades do setor privado, em benefício próprio ou de terceiros, para que essa pessoa pratique ou se abstenha de praticar um ato com violação dos seus deveres (CONSELHO DA EUROPA, 1999).

Nesse contexto, Sanseverino (2017, p. 34) avalia que a Convenção Penal sobre Corrupção, do Conselho da Europa, traz três motivos para criminalização da corrupção praticada em âmbito privado: 1. "Proteção da confiança, lealdade e sigilo nas atividades econômicas"; 2. Proteção da concorrência; 3. Suprir lacunas quanto a punibilidade de agentes que poderia advir em virtude das privatizações.

Segundo Foffani (2013), o legislador europeu justifica a criminalização da corrupção privada ao compreender que os dois tipos de corrupção, isto é, pública e privada, constituem uma ameaça ao Estado Democrático de Direito, ao mesmo tempo em que ferem a concorrência na aquisição de bens e serviços e impedem o sólido desenvolvimento econômico.

Nesse contexto, em âmbito europeu, tanto a Ação Comum 98/742/JAI quanto a Decisão Quadro 2003/568/JAI do Conselho da Europa dizem respeito especificamente ao combate à corrupção praticado exclusivamente no setor privado.

A Decisão Quadro 2003/568/JAI, do Conselho da Europa (2003), de iniciativa de Dinamarca, em seu preâmbulo, alerta para o problema transnacional das práticas corruptas em âmbito privado e defende que a questão pode ser mais eficazmente contornada através de uma ação comum entre os países da União Europeia:

Conjuntamente com a globalização, os últimos anos trouxeram um aumento do comércio transfronteiriço de bens e de serviços. Qualquer corrupção no sector 
privado num Estado-Membro não é, portanto, apenas um problema interno, mas também um problema transnacional, que se combate mais eficazmente através de uma acção comum da União Europeia (CONSELHO DA EUROPA, 2003)

Em seu teor, a Decisão Quadro reconhece a importância de se combater corrupção, tanto em âmbito público quanto privado, e destaca que a prática pode "conduzir a distorções da concorrência em relação à aquisição de bens ou serviços comerciais e prejudicar um são desenvolvimento económico" (CONSELHO DA EUROPA, 2003), razão pela qual busca garantir que os Estados signatários criminalizem atos de corrupção no setor privado. Nesses termos:

1. Os Estados-Membros devem tomar as medidas necessárias para garantir que sejam consideradas infracção penal as seguintes condutas voluntárias, praticadas no exercício de actividades profissionais:

a) Prometer, oferecer ou dar, directamente ou por interposta pessoa, vantagens indevidas de qualquer natureza a uma pessoa que, a qualquer título, dirija uma entidade do sector privado ou nela trabalhe, em benefício dessa pessoa ou de terceiros, a fim de essa pessoa, em violação dos seus deveres, praticar ou se abster de praticar determinados actos;

b) Solicitar ou receber, directamente ou por interposta pessoa, vantagens indevidas de qualquer natureza, ou aceitar a promessa de tais vantagens, em benefício do próprio ou de terceiros, quando, a qualquer título, essa pessoa dirija uma entidade do sector privado ou nela trabalhe, a fim de, em violação dos seus deveres, praticar ou se abster de praticar determinados actos.

2. O n.o 1 aplica-se às actividades profissionais no âmbito de entidades com ou sem fins lucrativos.

3. Qualquer Estado-Membro pode declarar que restringirá o âmbito de aplicação do n.o 1 às práticas, relacionadas com a aquisição de bens ou de serviços comerciais, que impliquem ou possam implicar distorção da concorrência.

Nesse sentido, Venda (2017) chama atenção para o fato de que muito embora a Decisão-Quadro tenha consignado que os prejuízos gerados pela corrupção em âmbito privado possam afetar a livre concorrência, o instrumento deixou a cargo de cada país a opção por restringir, ou não, os tipos penais às condutas que implicam “distorção da concorrência". Por conta disso, a compreensão sobre o bem jurídico tutelado pode variar entre cada Estado signatário.

A Decisão Quadro da União Europeia (2003) é, na visão de Foffani (2011), o instrumento mais significativo sobre a temática, uma vez que seu conteúdo e fundamentação foram bem elaborados pelo legislador europeu, que também consignou, em seu preâmbulo, 
que com o aumento do comércio entre fronteiras nos últimos anos a corrupção privada não pode mais ser considerada problema particular e exclusivo de cada Estado.

A luta contra a corrupção praticada no âmbito público levou à percepção da importância de também se combater práticas corruptas cometidas exclusivamente na esfera privada, algo que decorreu não apenas de processos de privatização, mas também diante da constatação que a conduta também era prejudicial aos concorrentes e aos consumidores (ARGANDOÑA, 2003).

Os instrumentos analisados revelam uma tendência internacional de criminalização da corrupção privada e uma tentativa de uniformização da legislação de combate à corrupção, ante o reconhecimento de que a corrupção, praticada tanto em âmbito privado como em seu modelo tradicional, é prejudicial à concorrência e ao desenvolvimento econômico.

\section{A CORRUPÇÃO PRIVADA NO BRASIL}

Ainda é tímido no Brasil o debate envolvendo a criminalização da corrupção privada, prevalecendo no país a concepção de que a corrupção ocorre quando há envolvimento de um funcionário público (CHAVES, 2013). Talvez por isso, a tutela penal sobre a matéria ainda se mostra bastante incipiente, muito embora o país tenha ratificado a Convenção de Mérida que, como visto, incentiva os países signatários a criminalizar a conduta.

Não obstante, embora não exista previsão normativa específica sobre a corrupção privada no Brasil, não se pode falar em completa ausência de proteção jurídica no país para os atos corruptivos nessa seara, pois além de normas no âmbito civil há uma tutela penal, ainda que tímida, no artigo 195, inciso IX e $\mathrm{X}$ da Lei $9.279 / 96^{\dagger}$, que prevê os crimes de concorrência desleal, e alguns delitos previstos no Estatuto do Torcedor, que prevê penas para aqueles que praticam fraudes em eventos esportivos (art. 41-C $C^{\ddagger}, 41-D^{\S}$ e $41-E^{* *}$ da Lei 10.671) (DAVID, 2019).

\footnotetext{
† “Art. 195. Comete crime de concorrência desleal quem: (...) IX - dá ou promete dinheiro ou outra utilidade a empregado de concorrente, para que o empregado, faltando ao dever do emprego, lhe proporcione vantagem; $\mathrm{X}$ recebe dinheiro ou outra utilidade, ou aceita promessa de paga ou recompensa, para, faltando ao dever de empregado, proporcionar vantagem a concorrente do empregador;"

‡ “Art. 41-C. Solicitar ou aceitar, para si ou para outrem, vantagem ou promessa de vantagem patrimonial ou não patrimonial para qualquer ato ou omissão destinado a alterar ou falsear o resultado de competição esportiva ou evento a ela associado: Pena - reclusão de 2 (dois) a 6 (seis) anos e multa."

s“"Art. 41-D. Dar ou prometer vantagem patrimonial ou não patrimonial com o fim de alterar ou falsear o resultado de uma competição desportiva ou evento a ela associado: Pena - reclusão de 2 (dois) a 6 (seis) anos e multa."
} 
Os referidos tipos penais, entretanto, ao ver de parte da doutrina, não se mostram suficientes para coibir a prática no Brasil. Para David, ainda que as condutas previstas no Estatuto do Torcedor se aproximem do que ele defende como uma "tutela penal adequada da corrupção privada", o mesmo não ocorre com os delitos previstos na Lei de Propriedade Industrial, os quais se amoldam a um modelo de "matriz contratual empregatícia" o qual, a seu ver, não se mostra adequado (DAVID, 2019, p. 137).

Segundo Pierangeli (1997), o delito previsto no inciso IX do art. 195 da Lei 9.279/96, conhecido como "espionagem econômica", assemelha-se ao delito de corrupção ativa, previsto no art. 333 do Código Penal.

De maneira geral, no Brasil, a corrupção privada vem sendo contornada a partir de tipos penais esparsos, conforme esclarecem Prado e Rosseto:

\begin{abstract}
a proteção penal contra a corrupção privada tradicionalmente tem se valido de normas incriminadoras extraídas do âmbito dos delitos contra o patrimônio, como por exemplo, o estelionato (art. 171) e a apropriação indébita (art. 168); dos delitos contra o sistema financeiro (Lei 7.492/1976); dos delitos que tutelam a ordem econômica, em especial os arts. $4 .^{\circ}, 5 .^{\circ}$ e $6 .^{\circ}$ da Lei 8.137/1990; dos crimes contra o mercado de capitais, previstos na Lei 6.385/1976, tais como o delito de manipulação de mercado (art. 27-C) e o delito de uso indevido de informação privilegiada (art. 27-D); além de disposições penais previstas na Lei 9.279/1996, que regula os direitos e obrigações relativos à propriedade industrial, a qual prevê, em seu art. 195, IX e X, a corrupção ativa e passiva praticadas por particulares como modalidades do delito de concorrência desleal. (PRADO; ROSSETO, 2015, p. 3)
\end{abstract}

Ainda assim, falta no Brasil o desenvolvimento de um debate mais sério envolvendo a temática, notadamente diante dos compromissos assumidos pelo país, que ratificou tratados internacionais que instigam e aconselham a tipificação da corrupção privada.

\title{
4. CORRUPÇÃO PRIVADA NAS LEGISLAÇÕES ESTRANGEIRAS
}

Chaves (2013) alerta para a necessidade de que, em um mundo globalizado, exista uma política criminal alinhada entre os Estados, de forma que não haja desequilíbrio entre as relações econômicas estabelecidas nos diversos países, implicando em desproporção de

\footnotetext{
** "Art. 41-E. Fraudar, por qualquer meio, ou contribuir para que se fraude, de qualquer forma, o resultado de competição esportiva ou evento a ela associado: Pena - reclusão de 2 (dois) a 6 (seis) anos e multa."
} 
encargos jurídicos, o que ocorre quando, por exemplo, uma conduta é excessivamente punida em um país e não é punida em outro.

A despeito da existência de diversos instrumentos internacionais que buscaram orientar os Estados quanto à necessidade de criminalização da corrupção privada em seus ordenamentos internos, há grande heterogeneidade na legislação estrangeira no tratamento conferido à corrupção privada, levando à diferentes formas de estruturação dos tipos penais (GONTIJO, 2014).

Sobre esse aspecto, foi feito um estudo bibliográfico sobre como a doutrina especializada avalia os modelos de tipificação dessa modalidade de corrupção, especialmente no que diz respeito à legislação de países europeus, precursores na temática.

Foffani (2011) esclarece que a criminalização da corrupção privada é uma "tendência político-criminal", paulatinamente consolidada nos últimos anos. Aponta, todavia, que os modelos escolhidos pelos diferentes países para punir a prática são variados. As opções variam desde um modelo que iguala a corrupção privada com a corrupção que ocorre no setor público (caso da Suécia), passando por modelos que protegem a relação laboral e de cunho patrimonialista, a um modelo que protege a concorrência, isto é, a lealdade da competição econômica.

Na visão de Foffani (2011), o modelo mais significativo e também o que melhor se adéqua ao programa político criminal do legislador europeu é o Alemão, onde o delito possui um perfil econômico e visa a proteção da concorrência.

Inclusive, interessa observar que desde 1909, quando foi criado na Alemanha o delito de corrupção de empregados, o legislador alemão buscou proteger a "livre e leal concorrência" e "assegurar a lealdade nas relações econômicas concorrenciais", punindo delitos de corrupção privada (GONTIJO, 2014, p. 100).

Não obstante, segundo Greco e Guimarães (2017) em 2015, foi promulgada na Alemanha a "lei de combate à corrupção" e o legislador alemão alterou o crime de corrupção privada de forma a abranger novas condutas. Dessa forma, além da proteção à concorrência, atualmente a legislação alemã também passou a proteger as relações de trabalho (DAVID, 2019).

David (2019) avaliou as diferentes propostas estrangeiras e classificou-as em cinco diferentes grupos: 1. fidelidade contratual empregatícia ou laboral; 2. lealdade concorrencial; 3. tutela patrimonial; 4. Modelo unitário; e 5. modelo pluriofensivo, misto ou complexo. Para 
o autor, o modelo concorrencial, adotado na Alemanha, Espanha, Áustria e Colômbia é o modelo que melhor se adequaria "à tutela das relações corruptas no setor privado", na medida em que define um bem jurídico de natureza supraindividual e se harmoniza "à necessidade de intervenção estatal na esfera econômica".

Prado e Rosseto, por sua vez, em uma análise comparada da legislação estrangeira, apontam a presença de, pelo menos, quatro modelos de incriminação nos países europeus, os quais denominam: laboral; omnicompreensivo; patrimonial e proteção da livre concorrência.

Nesse contexto, tecem críticas quanto ao modelo laboral, adotado na Holanda e na França, na medida que o que se busca proteger é a relação de boa fé e fidelidade entre empregado e empregador, tutela essa que, na visão dos autores, viola princípios como o da lesividade (PRADO; ROSSETO, 2015).

O modelo omnicompreensivo faz referência à adoção de "um tipo unitário de corrupção, que envolve tanto a corrupção pública como a privada" (PRADO; ROSSETO, 2015, p. 4), não se exigindo que o sujeito passivo seja um agente público. Esse é o caso do ordenamento sueco. Busca-se com o tipo unitário contemplar lacunas eventualmente deixadas com privatizações, por exemplo. Além disso, a opção parte da ideia de que "a corrupção sempre gera ineficiência econômica e custos excessivos que acabam por onerar a todos os cidadãos, sejam eles administrados ou consumidores" (PRADO; ROSSETO, 2015, p. 5).

No modelo patrimonial, tutela-se o patrimônio social da empresa, ao passo que no último modelo, relativo à proteção da livre concorrência, tem-se como bem jurídico tutelado a livre concorrência, visando-se a proteção do bom funcionamento do mercado (PRADO; ROSSETO, 2015).

Sanseverino (2017), a semelhança, aponta a existência de diversos modelos de tipificação da corrupção privada, que variam de acordo com o bem jurídico tutelado, destacando os seguintes quatro: 1. lealístico, 2. patrimonial, 3. concorrencial e 4. unitário.

Nesse sentido, denomina de modelo Lealístico aquele adotado em países como França e Holanda e esclarece que o tipo penal visa a proteção da lealdade e da confiança nas relações privadas. A semelhança de Prado e Rosseto (2015), o autor questiona se a proteção da lealdade nas relações privadas se mostra suficiente para justificar intervenção do Direito Penal (SANSEVERINO, 2017).

O modelo patrimonial, segundo o autor, é aquele que busca a proteção do patrimônio do empresário, pressupondo, assim como no modelo lealístico, a violação de deveres por parte 
do funcionário. Já os países que adotam o modelo concorrencial, como é o caso da Alemanha, buscam com a criminalização da corrupção privada a proteção de um bem jurídico de natureza supraindividual, que é o correto funcionamento do mercado e a livre concorrência.

Por fim, o modelo unitário é aquele que prevê um único tipo penal para o combate à corrupção cometida tanto na esfera pública quanto na esfera privada, buscando-se, nas palavras do autor, "a tutela, de uma forma geral, de um correto sistema de cumprimento de funções e transações" (SANSEVERINO, 2017, p. 55).

Cabe nesse ponto, contudo, uma breve ponderação a respeito da classificação adotada por diversos autores no que diz respeito ao modelo unitário ou omnicompreensivo: Isso, porque o modelo unitário toma em conta aspectos distintos dos demais (lealístico, patrimonial e concorrencial, por exemplo), na medida em que mais se relaciona com a forma de previsão do tipo penal, que iguala a corrupção praticada na esfera pública à privada, do que com a efetiva opção quanto ao bem jurídico tutelado. Não obstante, o modelo unitário é usado como critério pelos diversos autores que se dedicaram à análise da temática.

Conforme demonstram os estudos que se preocuparam em analisar a legislação de diversos países acerca do formato de criminalização da corrupção privada, é possível perceber que não há consenso, nem mesmo entre os países europeus, precursores no debate envolvendo o tema, com relação à forma de tipificação da corrupção privada e ao bem jurídico protegido.

\section{CONSIDERAÇÕES FINAIS}

Depois que os países perceberam que a corrupção, praticada tanto no âmbito público quanto privado, gerava grande ineficiência econômica, houve um significativo avanço na luta contra as práticas corruptivas ao redor do mundo e, ao ver de Foffani (2011), a criminalização da corrupção privada é hoje uma tendência político-criminal e que vem sendo paulatinamente consolidada nas últimas décadas.

No período da edição do Foreign Corrupt Practices Act, os Estados percebiam que o fenômeno da corrupção é prejudicial aos negócios, anticompetitiva, leva a uma distorção de preços e ainda coloca empresas honestas em uma situação de desvantagem concorrencial.

Após a edição do FCPA, muitas organizações internacionais, (OEA, OCDE, ONU, UE) aderiram aos esforços de combate à corrupção e criaram documentos visando a harmonização da repressão de práticas corruptas e aos poucos o combate à corrupção privada 
também passou a ganhar atenção da comunidade internacional, que emitiu documentos visando a sua prevenção e punição.

A implementação de uma política criminal que aborda a corrupção praticada entre particulares guarda relação direta com os processos de privatização e com a maior complexidade da atual dinâmica econômica empresarial, decorrente de globalização (GONTIJO, 2014), além de se revelar uma tendência internacional para frear a ineficiência econômica e garantir livre concorrência.

É crescente nesse cenário a preocupação internacional em coibir atos fraudulentos no âmbito do setor privado, promovendo a ética empresarial e assim garantindo a livre concorrência (CHAVES, 2013).

Paralelamente a isso, contudo, a doutrina aponta grande heterogeneidade no que se refere ao tratamento conferido à corrupção privada entre os diversos países e instrumentos supranacionais.

O que se pode concluir, é que o movimento internacional de combate à corrupção praticada entre particulares decorreu de um movimento maior de combate global contra a corrupção, mas que, na esfera criminal e a despeito de alguns esforços em âmbito supranacional, ainda não encontra consenso quanto à forma de tipificação.

\section{REFERÊNCIAS}

ARGANDOÑA, Antonio. Private-to-private Corruption. Journal of Business Ethics 47: p. 253-267, 2003.

BRASIL, Decreto no $\mathbf{5 . 6 8 7}$, de 31 de janeiro de 2006. Promulga a Convenção das Nações Unidas contra a Corrupção, adotada pela AssembléiaGeral das Nações Unidas em 31 de outubro de 2003 e assinada pelo Brasil em 9 de dezembro de 2003, Brasília, 31 de janeiro de 2006.

CARNEVALI, Raúl R.; ARTAZA, Osvaldo V.. La naturaleza pluriofensiva y transnacional del fenómeno de la corrupción. Desafíos para el derecho penal. Revista Brasileira de Ciências Criminais, v. 138, p. 17 - 57, Dez., 2017.

CHAVES, Anna Cecília Santos. A corrupção Privada no Brasil. REVISTA JURÍDICA ESMP-SP, v. 4, p, 231-260, 2013.

CONSElHO DA EUROPA. Ação Comum de 22 de Dezembro de 1998. Disponível em: $<$ https://eur-lex.europa.eu/legal-

content/PT/TXT/PDF/?uri=CELEX:31998F0742\&from=PT>. Acesso em: 22 out. 2020. 
CONSElHO DA EUROPA. Criminal Law Convention on Corruption. ETS No.173.

Strasbourg, 27/01/1999.

Disponível

em:

$<$ https://rm.coe.int/CoERMPublicCommonSearchServices/DisplayDCTMContent?documentI

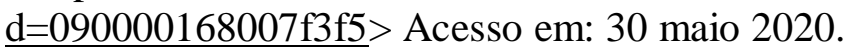

CONSELHO DA EUROPA. Decisão-Quadro 2003/568/JAI DO CONSELHO de 22 de Julho de 2003. Disponível em: <https://eur-lex.europa.eu/legalcontent/PT/TXT/PDF/?uri=CELEX:32003F0568\&from=PT>. Acesso em: 22 out. 2020.

COSTA, Sylvia Chaves Lima. A nova face da corrupção frente à tutela da ordem econômica. In: DE LA TORRE, Ignacio Berdugo Gómez; BECHARA, Ana Elisa Liberatore (coord.) Estudios sobre la corrupción Uma Reflexión Hispano Brasileña. Centro de Estudios Brasilenos / Universidad de Salamanca. 1 ed, 2012.

DAVID, Décio Franco. Tratamento Penal da Corrupção Privada a partir de um sistema penal integral de matriz significativa. 20019. Tese (Doutorado em Ciência Jurídica) Universidade Estadual do Norte do Paraná, Jacarezinho, Paraná

DE BRITO, Alexis Couto. A “Lei Anticorrupção" e o Direito Penal Corrupção no setor Público e Privado. Revista Duc In Altum Cadernos de Direito, vol. 11, nº 25, set.-dez., 2019.

FOFFANI, Luigi. LA CORRUPCIÓN EN EL SECTOR PRIVADO: Iniciativas internacionales y derecho comparado. Revista Brasileira de Ciências Criminais, vol. 81/2009, p. 48 - 60, Nov. - Dez., 2009

GIL, Antonio Carlos. Métodos e Técnicas de Pesquisa Social. 6 ed. São Paulo: Atlas, 2008.

GONTIJO, Conrado Almeida Corrêa. O crime de corrupção no setor privado: estudo de direito comparado e a necessidade de tipificação do delito no ordenamento jurídico brasileiro. 2014. Dissertação (Mestrado Programa de Pós-graduação em Direito, Direito Penal, Medicina Forense e Criminologia) Universidade de São Paulo, USP.

GRECO, Luís; GUIMARÃES, Adriano Teixeira. Aproximação a uma teoria da corrupção. Revista Brasileira de Ciências Criminais. v. 134. p. 159 - 188, ago, 2017.

MARTÍN, Adán Nieto. La privatización de la lucha contra la corrupción. In ZAPATERO, Luiz Arroy; MARTÍN, Adán Nierto (Diret). El derecho penal economico en la era compliance. Valencia. Ed. Tirant lo Blanch. 2013.

OCDE. Convenção sobre o Combate da Corrupção de Funcionários Públicos Estrangeiros em Transações Comerciais Internacionais. 1997. Disponível em: http://www.oecd.org/daf/anti-bribery/ConvCombatBribery_ENG.pdf. Acesso em 22 nov. 2020.

OEA. Convenção Interamericana Contra a Corrupção. 1996. Disponível em http://www.oas.org/juridico/portuguese/treaties/b-58.htm. Acesso em 05 nov. 2020. 
ONU. Convenção das Nações Unidas Contra a Corrupção. 2003. Disponível em: https://www.unodc.org/documents/lpo-

brazil//Topics_corruption/Publicacoes/2007_UNCAC_Port.pdf. Acesso em: 11 nov. 2020.

PIERANGELI, José Henrique. Crimes de Concorrência Desleal (Lei 9.279 de 14.05.1996 art. 195). Revista dos Tribunais. vol. 738/1997, p. 467 - 495, Abr. 1997.

PRADO, Luiz Regis; ROSSETO, Patrícia Carraro. Contributo ao estudo da corrupção delitiva entre particulares. Revista Brasileira de Ciências Criminais, vol. 114/2015, p. 51 97, Mai. - Jun., 2015.

SANSEVERINO, Enriso Rilho. O crime de corrupção no setor privado e o seu tratamento em uma perspectiva em face dos interesses tutelados. 2017. Dissertação (menção em Ciências Jurídico-Criminais) Faculdade de Direito Universidade de Coimbra.

USA. Criminal Division of the U.S. Department of Justice and the Enforcement Division of the U.S. Securities and Exchange Commission. FCPA - A Resource Guide to the U.S. Foreign Corrupt Practices Act. Second Edition. Disponível em: https://www.justice.gov/criminal-fraud/file/1292051/download. Acesso em: 20 out. 2020. 